\title{
CLINICAL ECONOMICS - IT IS ABOUT VALUES NOT ABOUT MONEY
}

\section{Franz Porzsolt*}

Corresponding author: Franz Porzsolt - franz.porzsolt@uniklinik-ulm.de

*Health Care Research and Clinical Economics, Dept. General and Visceral Surgery, University Hospi-tal

Ulm, 89081 Ulm, Germany and Institute of Clinical Economics (ICE) e.V., 89081 Ulm, Germany.

\section{A B S T R A C T}

Clinical Economics emerged from the field of medical oncology where the need of balancing harm and benefit is most obvious. It is explained that the principle of complete economic analyses in health care include both non-monetary (values) and monetary dimensions (budgets). Including the perspectives of individual patients, of doctors and of managers are equally important when decisions have to be made. Clinical Economics offers solutions to five major challenges of health care assessment and provision. 
During the past 25 years, the medical profession has been subjected to an economizing process.

Economization was considered as a new type of health care management and was well defined by Porter \& Teisberg': "The original idea of 'managed care' was simple and elegant - a primary care physician close to the patient would ensure that the care delivered was neither too much nor too little, involved appropriate specialists, and reflected the individual patient's needs and values."

This brief description of the actual service provided by the managed care concept requires the difficult balance between too much and too little of patient care. Monetary aspects cannot be found in this original concept. In his original concept the authors speak of a service provided by a physician, which we postulated with a nearly identical content in the field of medical oncology $y^{2,3}$ referred to as "Clinical Economics" 4,5 .

The term Clinical Economics describes the physicians' contributions in guiding the healthcare system. This system will be functioning when both physicians and economists make complete economic decisions. The complete economic analysis includes three components, what has to be given up (the costs), what will be gained (the consequences) and the comparison of at least two possible options (e.g. two different treatments). It is shown in Figure 1 that physician' decisions have to include the patient's perspectives that are related to non-monetary values. The economists' decisions have to include the institution's or company's perspectives and are related to monetary values. It is plausible that physicians' and economists' decisions require specific attitudes, skills and knowledge and can neither be exchanged nor replaced by each other. The medical and financial success of the institution will depend on the synergism of physicians and economists. The difficult part of this synergism has to be contributed by physicians. They have to provide the evidence that confirms the value of health care.

\section{Complete economic analysis in health care}

Physicians compare non-monetary values (costs and consequences from the patient perspective) of options 1 und 2 .

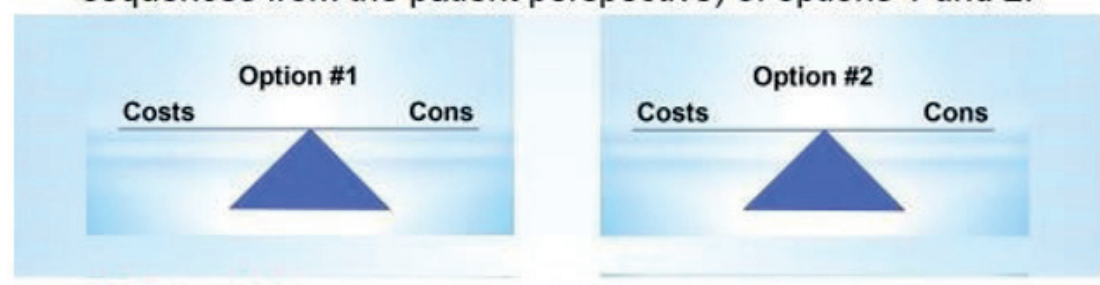

Economists compare monetary values (costs and consequences from the company perspective) of option 1 und 2 .

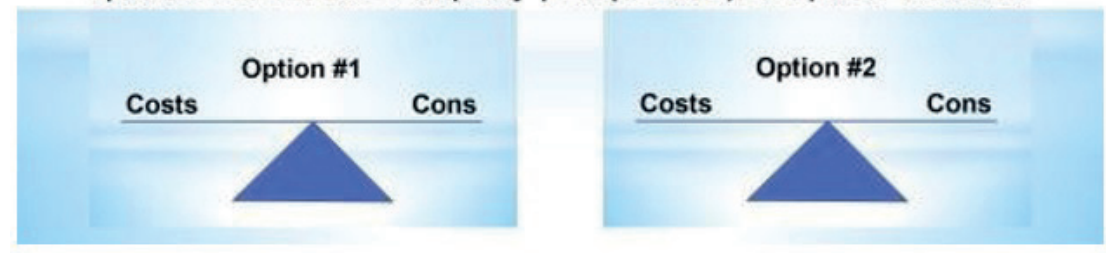

Figure 1: Complete economic analysis. The complete economic analysis in health care includes costs and consequences of at least two alternative options from the perspectives of the physician (including the patient perspective) and of the economist. Both non-monetary and monetary values have to be balanced to provide the most efficient solutions of health care challenges. 


\section{THE RISKS}

From the viewpoint of economists, the managed care movement has been gaining in importance in the healthcare system because the successes of profit-making management appeared to confirm the concept. This development appraised as positive by economists is counteracted by a growing resignation among physicians. Physicians' traditional freedom of medical decision-making is being distinctly throttled. Financial arguments are forcing increased regulation of medical care. A growing army of controllers which monitor compliance to standards has increased the workload in out-patient clinics and hospitals.

Whether these changes in the structures and processes of care have also improved the quality of healthcare provision, i.e., more effectively reducing patient complaints and fears, could not hitherto be confirmed. It is known that many scientific publications lack validity ${ }^{6}$ and international guidelines for treatment of identical types and stages of cancer vary considerably in their recommendations ${ }^{7}$. These recommendations are sometimes supported by clinical studies of rather poor quality ${ }^{8}$. Monitoring structural and procedural improvements is not enough. It has to be shown that changes finally lead to an improved outcome quality. Outcome quality can be demonstrated when Patient Related Outcomes (PROs) will be assessed.

PRO measures are, however, not always easy to implement for several reasons. The time interval between intervention and outcome is in healthcare usually longer than in industrial production. The benefit of most preventive programs can be demonstrated only 10-15 years after begin of a successful program. Unknown natural courses of diseases make it difficult to demonstrate the benefit of health services. The compliance of patients as well as the interest of scientists and definitely the interest of politicians will have decreased a decade after initiation of a program. Therefore, we have to provide convincing and reproducible evidence that confirms the availability of reliable short-term PROs. Patients, scientists, investors, and politicians expect to be "rewarded" in time for the burden and risks they accept. It is our job to identify the valid PROs that can be assessed within acceptable intervals. Another important condition is the doctor-patient relationship. Neglecting the trusting relationship between doctor and patient carries a high risk of losing fundamental parts of essential healthcare provision. The importance of considering patient and doctors preferences and the principle of "perceived safety" (feeling safe) are equally essential for successful healthcare provision.

In summary, Clinical Economics suggests to solve five major challenges in the assessment of health outcomes.

1. The selection of an appropriate surrogate parameter is often the only possibility to solve the problem of long time intervals between intervention and assessment of the final outcome.

2. The "Choosing Wisely" project of the foundation of the American Board of Internal Medicine addresses the need to waive unnecessary health services. Incentives should be discussed to support the implementation of this important strategy.

3. Patient Related Outcomes (PROs) should be assessed under day-to-day conditions to reflect the real world effectiveness.

4. One of the most efficient ways to guarantee high quality health care is the education of the readers of scientific literature to identify low validity publications and to avoid the implementation of poor and impracticable recommendations in daily practice i.e. prevention of useless services.

5. Finally, we have to develop the sensitivity towards the existing influence of preferences and perceptions of patients and colleagues on clinical outcomes.

The core interest of Clinical Economics is to develop and to offer solutions for these five challenges.

\section{SOLUTIONS}

These solutions should be related to the changed relationship between the medical profession and the public as requested by Donald Irvine, President of the Royal Society of Medicine": "The relationship between the medical profession and the public is changing, and the professionalism of doctors must 
evolve accordingly. What has not changed is the fact that the public need doctors who are knowledgeable and skilled, ethical and committed... As doctors our foremost ethical duty is to serve our patients and the community to the best of our ability. The same duty falls on politicians and managers, even if their ethical codes are a little less well defined. We have to start respecting and understanding each other's values and motives. We may then begin to trust each other."

Patients are beginning to realize that the traditional family doctor, who has taken care of the family for a generation and is aware of all the ups and downs of three generations living under the same roof, will no longer exist in the future. Respecting and understanding each other's values is probably the core principle that generates trust. Trust is the essential condition of successful health care. The suggested solutions to the five major challenges contribute to form the new relationship between the medical profession and the public.

1. To investigate the correlation of surrogates and final endpoints two of our students ${ }^{10,11}$ analyzed the results of 200 clinical studies that compared two cancer treatments and assessed both the TimeTo-Progression (TTP) as surrogate outcome and Overall Survival (OS) as final endpoint. Significant differences in OS were confirmed in only $50 \%$ of the studies that demonstrated a significant difference in TTP. If no difference was demonstrated in TTP a significant difference in OS was observed in less than $5 \%$ of studies. It can be concluded that a significant difference in TTP justifies continuation of a clinical trial to assess OS. If the TTP is not different in two treatments it is unlikely that differences in OS will be observed.

2. The implementation of the Choosing Wisely strategy may be benefit from a discussion of medical societies with health insurance companies about the possible re-investment of the saved resources. Wise decsions will be rewarded when the saved expenditures for unnecessary services will be made available to cover the costs for useful services that could so far not be covered by the available budgets. These rewards will function as incentive for implementation of the Choosing Wisely strategy ${ }^{12}$.

3. A consensus to describe real world effects (effectiveness) is essential. A proposal on a
"Pragmatic Controlled Trial" was described recently ${ }^{13}$. The Choosing Wisely strategy recognized that effects observed under ideal study conditions (efficacy) will not necessarily be useful to patients under real world conditions (effectiveness). When the effectiveness can be assessed demonstration of efficacy only may in many situations no longer justify the payment for health care.

The conscientious selection of appropriate PROs in real world conditions is an unmet challenge. For fair definition of the appropriate PROs the patients preferences on risks and chances have to be respected. It should be considered that the expressed preferences depend on the validity of the information given to the patients.

4. As the entire process of medical decision making depends on the validity of information the experience of medical decision makers to distinguish valid and not valid scientific publications will strongly influence the quality of health services. The available tools for assessment of the validity of scientific publications have been summarized ${ }^{14}$. The standardized and continuous assessment of the validity of publications is essential as various powerful conflicts of interest, commercial or academic, will always jeopardize the validity of scientific products.

5. The paradigm of Randomized Controlled Trials (RCTs) enabled a considerable progress in clinical research but also influenced the academic appreciation of subjective perceptions and preferences. Using the example of safety it is accepted that our safety-related decisions may be influenced by objective data but are not depending only on objective data such as risks. Risks are defined by incidence and size of damage. The safety decisions we make depend finally on the subjective perception of objective risks which we call "perceived safety". 
Figure 2 shows the "safety loop"15 which describes the relationship of objective risk, of the subjective perception of objective risks, the decisions that are based on the subjective perceptions of the risks and finally the effects of the subjective decisions on the modulation of the objective risk.

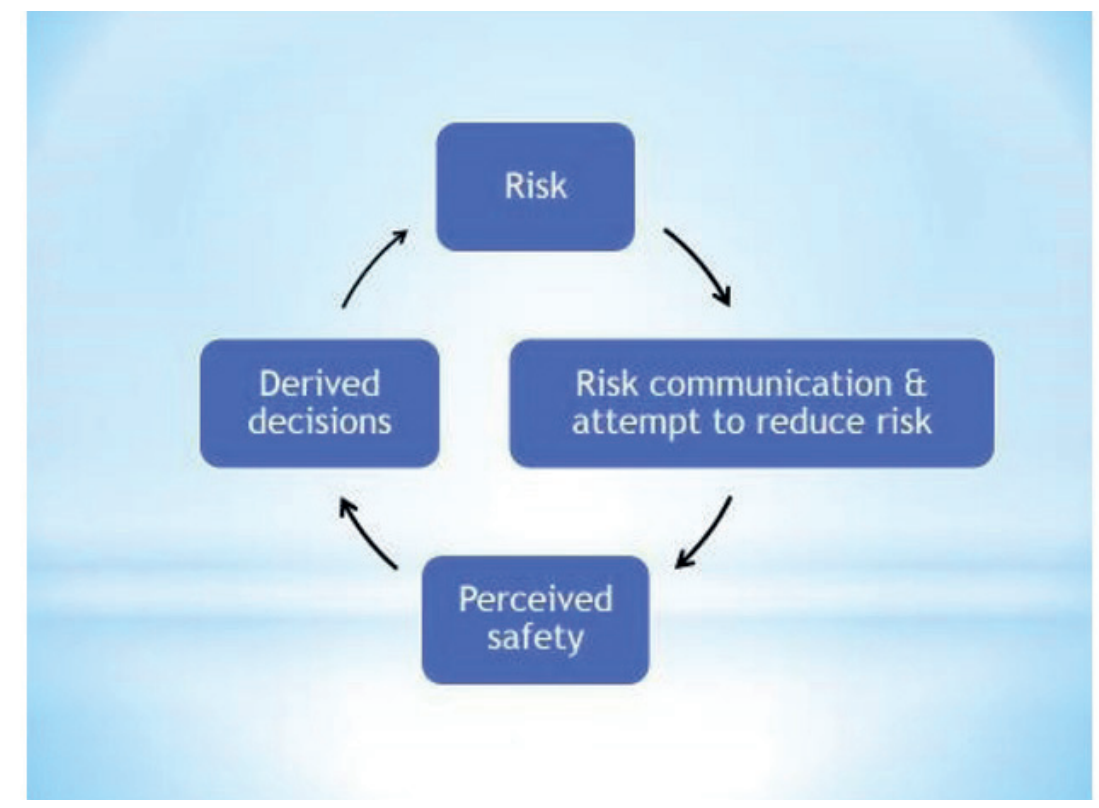

Figure 2: The „safety loop“. Objective risks induce the communication of risks and attempts to reduce the risks. The risk communication leads to the subjective per- ception of the risks that is different in different individuals. The subjective percep- tion is tha basis for the derived decisions and the decisions influence the risk.

The same is true with scientific decisions including the application of clinical guidelines. These are influenced by scientific evidence but have, at the end, to agree with the subjective perceptions of the decision maker. David Sackett and colleagues name the subjective perception of science and experience "individual clinical expertise"16. We used the phrase "internal evidence" to describe the individual doctor's current knowledge and to contrast it to the "external evidence" represented mainly by the published literature ${ }^{17}$.

Muir Gray is talking about "values" that control our decisions ${ }^{18}$.

\section{CONCLUSIONS}

The above examples are used to show that the considerations and methods summarized as Clinical Economics are necessary to balance health care decisions but are not generally considered. The correlations of surrogates and final endpoints are important for two types of discussions and decisions. In case of policy decisions it is important to balance high expenditures for services and rather low success rates (inefficient services) with more efficient services to avoid expenditures that are urgently needed for solving other health problems. As far as individual decisions are concerned some doctors and patient accept even high risks of harm associated with small chances of success while others generally prefer to avoid high risks.

The example of Choosing Wisely demonstrates that economic decisions are made in health care. The chance to waive unnecessary services will increase when the saved resources can be used to improve the quality of care according to the provider's values.

Reliable results that describe real world outcomes are the backbone of future economic decisions in health care. Discussions about monetary costs will remain hypothetical unless the benefit generated under real world conditions can be demonstrated. Therefore, the development of methods (e.g. Pragmatic Controlled Trials) and strategies for description of real world outcomes will guarantee the return of investment. Supported by medical students we confirmed that 
the validity of a large proportion of clinical trials is rather low ${ }^{19}$.

Low validity information is one of seven conflicts of interest that influence the quality and safety of health care provision ${ }^{20}$. These conflicts of interest are hard to control. Education is the most efficient strategy to reduce the effects of these conflicts of interest. The new generation of medical doctors has be aware of these risks and has to acquire the necessary attitudes, skills and knowledge to differentiate valid and not valid scientific publications. Once the editors of scientific journals realize that the readership's knowledge about validity is changing the validity of publications in scientific journals will also change. Concerning preferences and perceptions we can assume a general consensus on the principle of "value-based decisions". This means we all make decisions based on our individual values influenced by various sources of scientific information. The preferences of patients who agree or refuse to participate in a RCTs are different. Consequently, we may postulate that some values associated with quality of life indicators and other PROs are also different in these two cohorts of patients. Until now we did not pay much attention to differences in preferences and perceptions of different cohorts of patients. Colleagues at the Mayo Clinic $^{21}$ suggest directing attention to two factors in the professionalization of medical doctors - personal factors and surrounding factors. Stress, well-being, individual characteristics, and interpersonal qualities are personal factors. The institutional culture, formal and informal curricula, and the definition of characteristics of the physician's everyday routine are surrounding factors. Under the title "Time for hard decisions on patient-centered professionalism" 20 describes that patients want doctors who are competent, respected, honest, and who can communicate.

To implement sustainable new concepts in our educational institutions ${ }^{22}$, it will no longer suffice to reward students' performance with good grades ${ }^{23}$. In a first step we should concretely distinguish the abilities which characterize the medical professionalism. This will only succeed if the educational institutions themselves manage to create a climate on their own premises which, aside from the sober, scientificallyoriented concept of evidence-based medicine, encourage an informal system in which empathy is expressed and the patients can be given hope. Some call this "higher professionalism" in contrast to basic professionalism ${ }^{24}$. Finally, in whichever way possible, the achievement of the actual goal - achieving maximal success in healthcare provision with minimal expense - must be tested. Clinical Economics can provide the necessary scientific considerations if the criteria of medical professionalism are fulfilled and the administrative authorities support the concept.

\section{REFERENCES}

1. Porter M, Teisberg E. Redefining Health Care - Creating Value-Based Competitionon Results. Harvard Business School Press; 2006. P.76.

2. Porzsolt F, Gaus W. Wirksamkeit und Nutzen medizinischer Maßnahmen: Ein Beitrag zur Optimierung des Gesundheitssystems. Der Klinikarzt. 1993;1 2:522-528. German.

3. Porzsolt F. Nutzen von

Früherkennungsmaßnahmen, was ist gesichert? ATO. 1993; 1 2:45-47. German.

4. Porzsolt F, Klinische Ökonomik - Eine Forderung der Gesellschaft an die Ärzte. Münch med Wschr. 1994;136:221-225. German.

5. Porzsolt $f$, Kaplan RM. CLINECS: Strategy and Tactics to provide Evidence of the Usefulness of Health Care Services from the Patient's Perspective (Value for Patients). In: Porzsolt F, Kaplan RM (eds.) Optimizing Health - Improving the Value of Healthcare Delivery. New York: Springer; 2006. P.1-9

6. Allison DB, Brown AW, George BJ, Kaiser KA. $A$ tragedy of errors. Mistakes in peer-reviewed papers are easy to find but hard to fix. Nature. 2016;530(7588):27-29. doi:10.1038/530027a.

7. Baver K, Schroeder M, Porzsolt F, Henne-Bruns

D. Comparison of international guidelines on the accompanying therapy for advanced gastric cancer: reasons for the differences. J Gastric Cancer. 2015;15(1):10-18. doi: 10.5230/ igc.2015.15.1.10. 
8. Baver K, Porzsolt F, Henne-Bruns D. Validity of the MAGIC study: Sufficient for Recommendations?. Hepatogastroenterolgy. 2013;60(1 27):18221824.

9. Irvine $D$. The changing relationship between the public and the medical profession. J R Soc Med. 2001 ;94(4):162-169.

10. Weber A. Time to progression versus progression free survival als Surrogatparameter für das Überleben in onkologischen Studien [Doctoral thesis]. Medical faculty: University of Ulm, Germany; 2010.

\section{Serebrinski R. Prädiktiver Wert der}

Surrogatparameter "Time-to-Progression" und „Progression-Free Survival" für das „Overall Survival" in klinischen onkologischen Studien [Doctoral thesis]. Medical faculty; University of Ulm, Germany. 2011 . German.

12. Porzsolt F, Correia LC. Klug entscheiden: Nicht nur Schaden vermeiden, auch Nutzen mehren. DÄB (in press); 2016. German.

\section{Porzsolt F, Rocha NG, Toledo-Arruda AC,} Thomaz TG, Moraes C, Bessa-Guerra TR et al. Efficacy and Effectiveness Trials Have Different Goals, Use Different Tools, and Generate Different Messages. Pragmatic and Observational Research. 2015;6:47-54. doi: http://dx.doi.org/10.2147/ POR.S89946.

14. Porzsolt F, Braubach P, Flurschütz PI, Göller $A$, Sailer MB, Weiss M et al. Medical Students Can Help Avoid the Expert Bias in Medicine. Creative Education. 2012;3(Special Issue): $1115-1121$. doi: $10.4236 /$ ce.2012.326167

15. Porzsolt F. Evidence-based Risk Management: safety means "perception of risk". 4th World Congress on Clinical Safety; Vienna, Austria; 2015. P. 28-30.

16. Sackett DL, Richardson WS, Rosenberg W, Haynes RB. Evidence-Based Medicine: How to Practice and Teach EBM. 1 st edition. Toronto: Churchill Livingstone; 1997.
Ruatti $\mathrm{H}$, Meier $\mathrm{H}$ et al: Evidence - based decision making. The six step approach. Editorial. EvidenceBased Medicine. 2003;8:165-6. doi:10.1136/ ebm.8.6.165.

18. Muir Gray JA. Evidence based policy making. BMJ. 2004;329:988-989. doi: 10.1136/ bmj.329.7473.988.

19. Porzsolt F. Risk Management in Health Care Lessons learned from Clinical Economics. In: Huber M, Moormann C, Proske D: Proceedings of the 10th International Probabilistic Workshop, Stuttgart; 2012.

20. West CP, Shanafelt TD. The influence of personal and environmental factors on professionalism in medical education. BMC Med Educ. 2007;7:29. doi: 10.1 186/1472-6920-7-29.

21. Irvine DH. Time for hard decisions on patient-centred professionalism. Med J Aust. 2004;181(5):271-274.

22. Braddock III CH, Eckstrom E, Haidet P. The "New Revolution" in Medical Education: fostering professionalism and patient-centered communication in the contemporary environment. J Gen Intern Med. 2004; 19(5 Pt 2):610-611. doi: $10.1111 / j .1525-1497.2004 .45003 . x$.

23. Shrank WH, Reed VA, Jernstedt GC. Fostering professionalism in medical education: a call for improved assessment and meaningful incentives. J Gen Intern Med. 2004;19(8):887-892. doi: $10.1111 /$ i.1525-1497.2004.30635.x.

24. Bryan CS. Theodore E. Woodward Award. HIV/ AIDS, ethics, and medical professionalism: where went the debate?. Trans Am Clin Climatol Assoc. 2003; 1 14:353-367.

17. Porzsolt F, Ohletz A, Thim A, Gardner D, 